\title{
Synergistic Effect of Physical Therapy Plus Pharmacological Therapy with Eperisone in Tension-Type Cervicalgia
}

\author{
C. Asaro, D. Scaturro, S. Tomasello, L.G. Tumminelli, G. Letizia Mauro \\ Department of Physical Medicine and Rehabilitation of University Hospital "P. Giaccone", Palermo, Italy
}

\section{CORRESPONDING AUTHOR: \\ Giulia Letizia Mauro \\ Department of Physical Medicine \\ and Rehabilitation \\ University Hospital "P. Giaccone" \\ Via del Vespro 127 \\ 90100 Palermo, Italy \\ E-mail: giulia.letiziamauro@unipa.it \\ Phone: 3687876546}

DOI:

10.32098/mltj.04.2019.20

LEVEL OF EVIDENCE: 2B

\begin{abstract}
SUMMARY
Background. This study assessed the effect of eperisone + physical therapy compared with physical therapy alone on the alleviation of pain and disability experienced by patients with tension-type cervicalgia.

Methods. Patients with tension-type cervicalgia were randomized to eperisone + physical therapy (Group A) or physical therapy alone (Group B). Patients were assessed at baseline $\left(\mathrm{T}_{0}\right)$, after 4 -weeks' treatment $\left(\mathrm{T}_{1}\right)$, and at 2 months' follow-up $\left(\mathrm{T}_{2}\right)$. Outcome measures included the Numerical Rating Scale, the Italian version of the Neck Pain and Disability Scale, the Short Form-McGill Pain Questionnaire, and the Italian version of the Neck Disability Index.

Results. Ninety-eight patients (50 patients in Group A and 48 patients in Group B) completed the study. Pain and disability scores for all outcome measures were significantly lower at both $\mathrm{T}_{1}$ and $\mathrm{T}_{2}$ for patients in Group A compared with Group B (all $p<0.001$ ). A small, improvement between $T_{1}$ and $T_{2}$ was observed in Group A patients but not in Group B patients, and significantly more Group B than Group A patients were worse at 2 months' follow-up (all $p<0.001$ ).

Conclusions. Eperisone in synergy with physical therapy can be a valuable tool in the therapeutic management of patients suffering from tension-type cervicalgia.
\end{abstract}

\section{KEY WORDS}

multimodal treatment approach; muscle relaxant; neck pain.

\section{INTRODUCTION}

Neck pain is a disabling condition, with sufferers often experiencing periods of remission and exacerbation; for most individuals, complete resolution of symptoms and disability is not achieved (1).

Neck pain has been ranked by the Global Burden of Disease Study 2010 as the fourth leading cause of years lived with disability (2). Age, gender and genetics have been identified as non-modifiable risk factors for neck pain 3 and stress has been identified as a modifiable risk factor (4). More women than men experience neck pain and its prevalence peaks in middle age (3). The annual prevalence of neck pain has been estimated to range between $15 \%$ and $70 \%$, demonstrating the substantial heterogeneity in reported prevalence rates $(3,5,6)$.

Cervicalgia is localized pain that occurs towards the rear or side of the cervical spinal vertebrae, with sufferers experiencing either a sharp, stabbing pain or a dull, persistent pain in the neck, upper back or shoulders $(7,8)$. Symptoms of cervicalgia may include stiffness or spasms in neck muscles, movement-related pain when rotating in all directions, constant ache in the neck, tightness around the neck/ upper back, which may be tender to touch, and headaches $(7,9,10)$. Symptoms of cervicalgia may disappear within a few weeks, however, medical treatment may be required if the pain persists. 
Eperisone hydrochloride (40-ethyl-2-methyl-3-piperidinopropiophenone hydrochloride) is an analgesic and centrally acting muscle relaxant with a novel mechanism for the treatment of spasticity, muscle contraction and associated pain. Eperisone is indicated in the treatment of spastic paralysis caused by cerebrovascular disorders, spastic spinal paralysis, and spastic multiple sclerosis, and for the improvement of muscular contractions secondary to osteo-arthro-muscular pathologies (cervical arthrosis, scapulohumeral periarthritis, lumbosciatalgia, and myalgias) (11).

Treatment with eperisone alleviates muscle stiffness and pain caused by muscle spasm. Its mechanisms of action include: skeletal muscle relaxation, hemodynamic action, and analgesic activity, thereby offering a multimodal approach to pain management (12).

A systematic literature review found that eperisone may offer an effective treatment choice for patients with low back pain with minimal adverse effects and improved paraspinal blood flow, although the smaller sample size and shorter duration of the studies assessed prevented its definitive recommendation for the treatment of low back pain (13). It is therefore reasonable to suggest that eperisone may also be effective for the treatment of tension-type cervicalgia.

The aim of the current study was to assess the effect of eperisone + physical therapy compared with physical therapy alone on the alleviation of pain and disability experienced by patients with tension-type cervicalgia.

\section{MATERIALS AND METHODS}

\section{Patients}

Outpatients with tension-type cervicalgia who were undergoing treatment at the Physical Medicine and Rehabilitation Clinic of the University Hospital "P. Giaccone", Palermo, were included in the study. Patients were consecutively enrolled from March 2016 to April 2017 and were included in the study if they were aged between 20 and 70 years, affected by cervicalgia due to subcutis tension in the temporal muscle (from 4 weeks to 12 weeks temporal classification according to Crue and Pinsky) (14), had a positive trigger point, and had undergone a 7-day wash-out period from nonsteroidal anti-inflammatory drugs (NSAIDs) and myorelaxants. Exclusion criteria included: radiculopathy, rheumatic disease, presence of fracture, epilepsy, pace maker, chronic renal insufficiency and hepatic insufficiency, pregnancy, and neoplasm. Written, informed consent was obtained from the patients prior to study entry. The study was approved by the local Institutional Review Board (Ethical Committee of Palermo: 1 session of approval 16/05/2018 n. $05 / 2018$ ) in accordance with the ethical principles stated in the Declaration of Helsinki. The study meets the ethical standards of the journal (15).

Patients were randomized in two groups and received either eperisone + physical therapy (Group A) or physical therapy alone (Group B). For patients in Group A, eperisone hydrochloride $100 \mathrm{mg}$ was given twice a day for 15 days +20 sessions of physical therapy, which included transcutaneous electrical nerve stimulation (TENS) and $\mathrm{CO}_{2}$ Laser on the cervical rachis 5 days a week for a total of 4 weeks. Patients in Group B, who only received physical therapy, were treated with 20 sessions TENS and $\mathrm{CO}_{2}$ Laser on the cervical rachis 5 days a week for a total of 4 weeks.

Patients were assessed at baseline $\left(\mathrm{T}_{0}\right)$, at the end of the 4-week treatment period $\left(\mathrm{T}_{1}\right)$, and at follow-up, 2 months later $\left(\mathrm{T}_{2}\right)$. At each study visit, patients' pain and disability were assessed via a clinical examination and via questionnaires including the Numerical Rating Scale (NRS), the Italian version of the Neck Pain and Disability Scale (NPDS) (16), the Short Form-McGill Pain Questionnaire (SF-MGPQ) (17), and the Italian version of the Neck Disability Index (NDI) (18).

The NRS is based on a scale from $0-10$, in which "0" is the absence of pain and " 10 " is the worst pain the patient can imagine. Patients are asked to assign a score to the intensity of their pain.

The NPDS is a region-specific measurement scale that was developed based on the Million Visual Analogue Scale (19) and recommended by Wheeler and colleagues (20) for cervical pain and associated disability. It is a self-administered questionnaire consisting of 20 items which assess four dimensions of neck pain: neck pain/intensity, neck problems, effects of neck pain on emotions, and interference with activities of daily life (16). The 20 items are scored on a range of 0 to 5 , with a highest total score of 100 (= maximal pain). The SF-MGPQ is a useful tool to investigate the quality of pain. Designed in 1987, it is the short version of the MGPQ and allows individuals to identify the characteristics of the pain they experience, to detect minor clinical changes and to reflect further on the expectations and the unexpected features of pain ${ }^{17}$. Patients are asked to describe their perception of pain according to its intensity (none $=0$, mild $=1$, moderate $=2$, and severe $=3$ ).

The NDI questionnaire is designed to assess how neck pain affects a patients' ability to manage everyday life activities. Calculation of the NDI score is obtained by adding up the separate scores of the 10 sections (each section is scored from 0 to 5 where 0 relates to pain having no effect and 5 is pain having the highest impact on daily activities of life); the highest total score is 50 (18).

Changes in the NRS, NPDS, SF-MGPQ, and NDI for each patient were assessed at the end of the 4-week treat- 
ment period $\left(\mathrm{T}_{1}\right)$ and after the 2-month follow-up period $\left(\mathrm{T}_{2}\right)$. Patients with a reduction in the questionnaire score compared with the previous assessment were classified as "improved". If there were no changes, they were described as "unchanged". If a patients' pain/disability had worsened compared with the previous assessment (i.e., an increase in the questionnaire score), they were classified as "worsened".

\section{Statistical analysis}

Statistical analysis was performed using the SPSS Statistical Package software, ver. 20.0 (IBM Corp., Armonk, NY, USA). Demographics, clinical and symptom-related data, and treatment type are depicted in tables that show absolute frequencies and percentage relative frequencies for qualitative variables, and mean/median values, standard deviations, and minimum and maximum values for quantitative variables. Variations in pain and disability based on the NRS, NPDS, SF-MGPQ, and NDI scores were analyzed between the two treatment types using a generalized linear model (repeated measures analysis of variance). The paired sample t-test was used to assess pre- and post-treatment changes in each patient. The unpaired sample t-test assessed the differences between treatment groups. Where required, corrections for multiple comparisons were applied to the $p$-value.

To establish if there was an association between the administered therapy and the worsening of pain and disability during the follow-up period, a $\chi^{2}$ test was applied with correction for continuity. The relative risk (RR) was also calculated with a $95 \%$ confidence interval $(95 \% \mathrm{CI})$. The $\mathrm{RR}$ is the ratio of the incidence of cases with symptom worsening in Group B (physical therapy only) over the incidence of cases with symptom worsening in Group A (eperisone + physical therapy).

Values of $p<0.05$ were considered significant.

\section{RESULTS}

In total, 98 patients (50 patients treated with eperisone + physical therapy and 48 patients treated with physical therapy alone) were eligible for and included in the study; all patients completed the study and were included in the assessment.

Patient demographics and clinical features at baseline are shown in table I. Mean patient age was 41.6 years (range 24-69 years) and $69.4 \%$ of patients were female. At baseline, there were no significant between-treatment group differences in age, gender or in the patient outcome measures of the NRS, NPDS, and SF-MGPQ. Baseline NDI was significantly different for the two treatment groups (32.8 versus 30.4 for Group A versus Group B; $p<0.001$ ) (table I).
The change from baseline in pain and disability scores based on the NRS, NPDS, SF-MGPQ, and NDI questionnaires after 4-weeks' treatment and after 2-months' follow-up are shown in figure 1 . For patients treated with eperisone + physical therapy, pain and disability scores decreased significantly from $T_{0}$ to $T_{1}$ and from $T_{1}$ to $T_{2}$ for most outcome measures (all $p<0.001$ ), with the exception of the decrease in NRS score between $\mathrm{T}_{1}$ and $\mathrm{T}_{2}$, which was not significant. Pain and disability scores also decreased significantly from $\mathrm{T}_{0}$ to $\mathrm{T}_{1}$ for patients treated with physical therapy alone ( $p<0.001$ for all outcome measures), however these increased significantly between $\mathrm{T}_{1}$ to $\mathrm{T}_{2}(p<0.005$ for NRS and NPDS; $p<0.001$ for SF-MGPQ and NDI) showing that improvements in neck pain were not sustained after completion of the treatment.

Importantly, pain and disability scores for all patient outcome measures were significantly lower at both $T_{1}$ and $T_{2}$ for patients treated with eperisone + physical therapy compared with physical therapy alone (all $p<0.001$ for NRS, NPDS, SF-MGPQ, and NDI). The total change in pain and disability scores from $T_{0}$ to $T_{2}$ was also significantly lower for patients treated with eperisone + physical therapy versus physical therapy alone $(-4.9$ versus -2.2 for the NRS, -37.0 versus -18.0 for the NPDS, -9.7 versus -5.6 for the SF-MGPQ, and -24.6 versus -16.1 for the NDI, respectively; all $p<0.001$ ).

For an overview of changes in pain and disability scores observed for all outcome measures (NRS, NPDS, SF-MG$\mathrm{PQ}$, and NDI) during the study period, the percentage change between assessments was calculated (table II). Patients treated with eperisone + physical therapy not only maintained improvements observed after treatment (from $\mathrm{T}_{0}$ to $\mathrm{T}_{1}$ ), they also benefited from a further, albeit small, improvement between $T_{1}$ and $T_{2}$. Conversely, although the percentage change in pain and disability scores decreased from baseline to treatment end for patients treated with physical therapy alone (from $\mathrm{T}_{0}$ to $\mathrm{T}_{1}$ ), this was not maintained at the 2 -month follow-up assessment (from $\mathrm{T}_{1}$ to $\mathrm{T}_{2}$ ) with the increase in questionnaire scores showing a worsening of patients' pain/disability compared with the previous assessment. For all outcome measures, there was a greater decrease in total percentage change for patients treated with eperisone + physical therapy than physical therapy alone.

table III shows the change in the NRS, NPDS, SF-MGPQ, and NDI scores of each patient assessed after 4-weeks' treatment and at 2-months' follow-up compared with their previous assessment. For all patients, symptoms of pain and disability improved from baseline after 4-weeks' treatment regardless of treatment type. Symptoms of pain and disability either improved or were unchanged at the 2-month follow-up assessment compared with the end of the 4-week treatment period for most patients treated with eperisone + 
Table I. Patient demographics and clinical features at baseline.

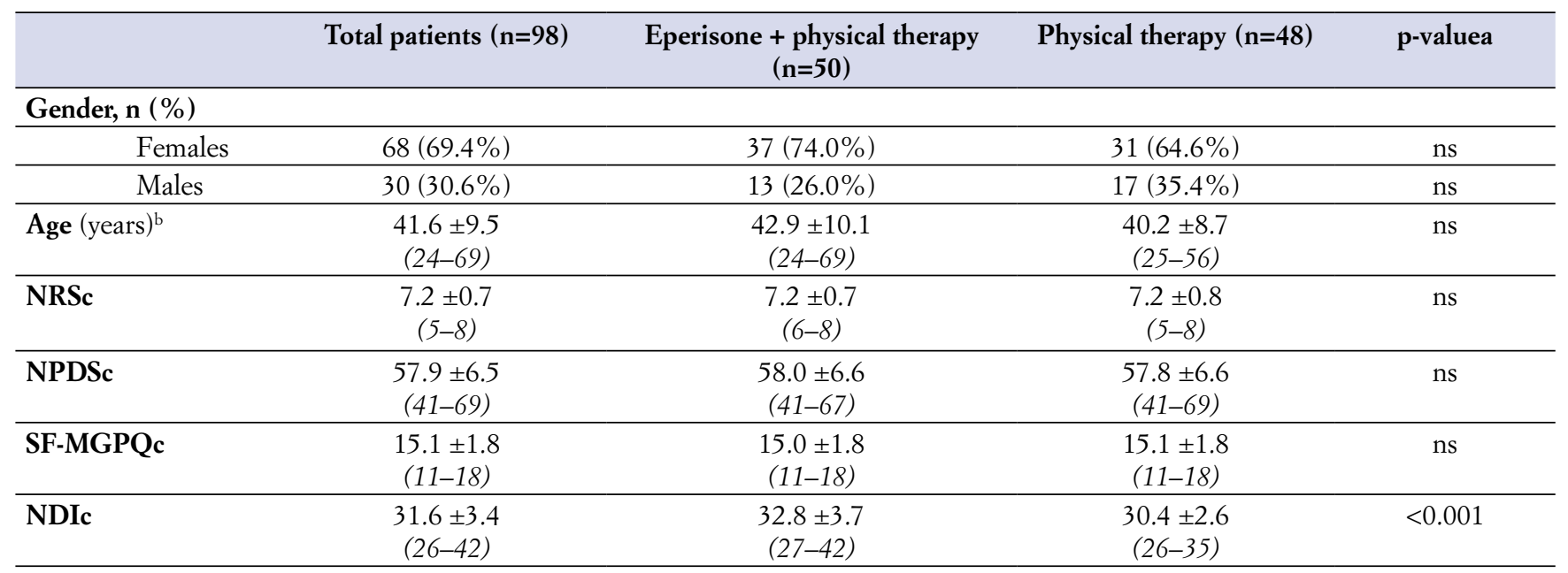

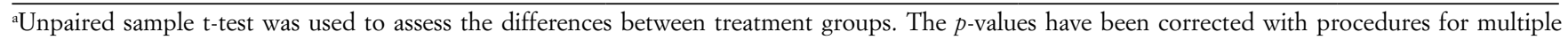
comparisons.

${ }^{\mathrm{b}}$ mean $\pm \mathrm{SD}$ (min-max).

${ }^{c}$ median $\pm \mathrm{SD}(\min -\max )$.

Abbreviations: n: number; NDI: Neck Disability Index; NPDS: Neck Pain and Disability Scale; NRS: Numerical Rating Scale; ns: not significant; SD: standard deviation; SF-MGPQ: Short Form - McGill Pain Questionnaire.

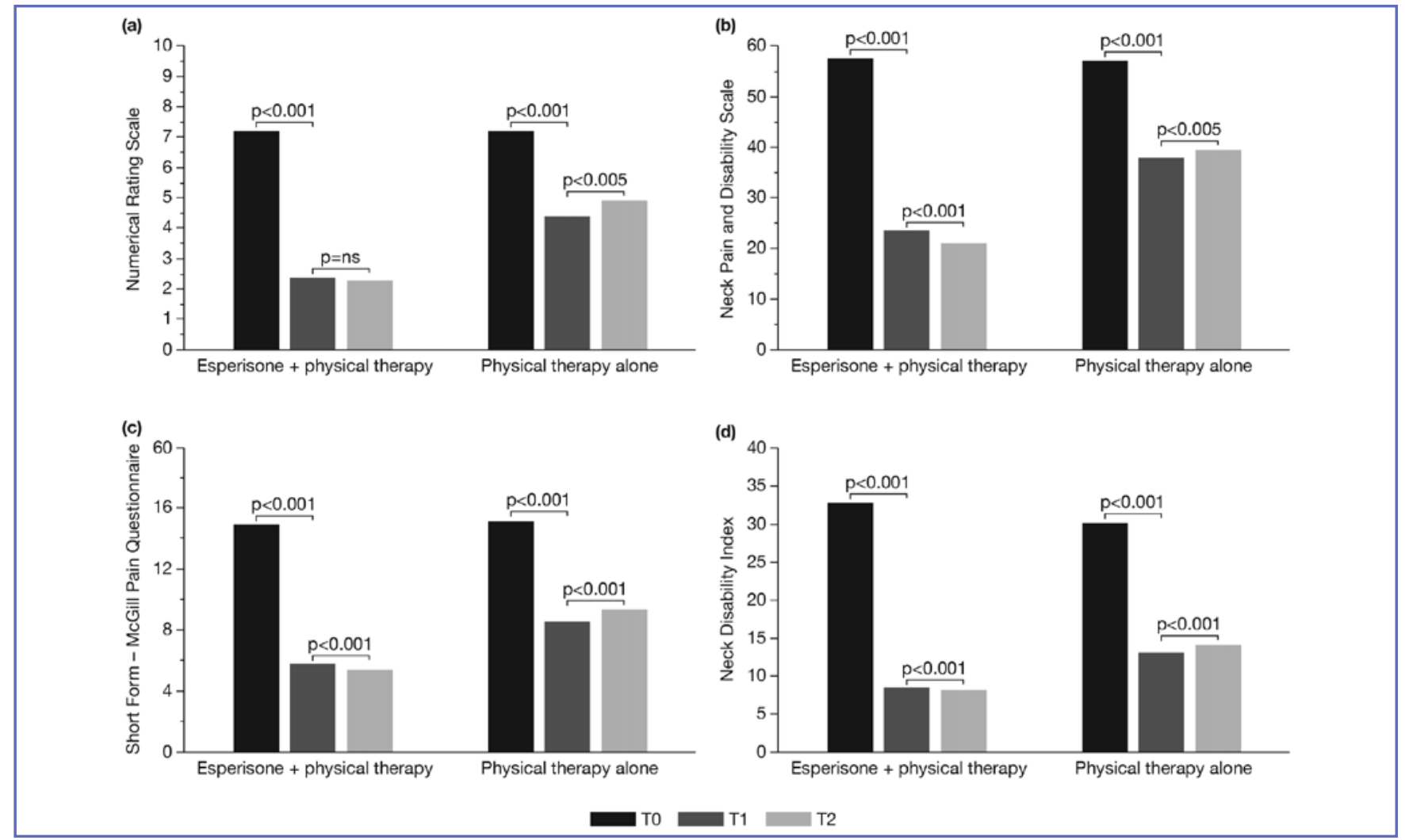

Figure 1. Patient outcome measures at T0 (baseline), T1 (after 4 weeks' treatment), and T2 (after 2-months' follow-up) for the (a) Numerical Rating Scale (b) Neck Pain and Disability Scale (c) Short Form - McGill Pain Questionnaire, and (d) Neck Disability Index. Abbreviations: ns: not significant. 
Table II. Percentage change in patient outcome measures observed during the study period.

\begin{tabular}{lcccccc}
\hline & \multicolumn{3}{c}{ Eperisone + physical therapy } & \multicolumn{3}{c}{ Physical therapy alone } \\
\hline & $\begin{array}{c}\Delta \% \text { from } \mathrm{T}_{0} \\
\text { to } \mathrm{T}_{1}\end{array}$ & $\begin{array}{c}\Delta \% \text { from } \mathrm{T}_{1} \\
\text { to } \mathrm{T}_{2}\end{array}$ & Total $\Delta \%$ & $\Delta \%$ from $\mathrm{T}_{0}$ to $\mathrm{T}_{1}$ & $\begin{array}{c}\Delta \% \text { from } \mathrm{T}_{1} \\
\text { to } \mathrm{T}_{2}\end{array}$ & Total $\Delta \%$ \\
\hline NRS & $-67.2 \%$ & $-0.5 \%$ & $-67.7 \%$ & $-38.8 \%$ & $8.1 \%$ & $-30.7 \%$ \\
NPDS & $-59.5 \%$ & $-4.2 \%$ & $-63.7 \%$ & $-34.2 \%$ & $3.4 \%$ & $-30.8 \%$ \\
SF-MGPQ & $-60.8 \%$ & $-3.2 \%$ & $-64.0 \%$ & $-42.6 \%$ & $5.4 \%$ & $-37.2 \%$ \\
NDI & $-73.5 \%$ & $-1.4 \%$ & $-74.9 \%$ & $-56.7 \%$ & $3.9 \%$ & $-52.8 \%$ \\
\hline
\end{tabular}

Abbreviations: $\Delta \%$ : percentage change; NDI: Neck Disability Index; NPDS: Neck Pain and Disability Scale; NRS: Numerical Rating Scale; SF-MGPQ: Short Form - McGill Pain Questionnaire.

Table III. Condition of the patients at the end of the 4-week treatment period $\left(T_{1}\right)$ and at 2-months' follow-up $\left(T_{2}\right)$ compared with their previous assessment.

\begin{tabular}{|c|c|c|c|c|c|c|c|}
\hline & & \multicolumn{3}{|c|}{ Eperisone + physical therapy } & \multicolumn{3}{|c|}{ Physical therapy alone } \\
\hline & & Improved & Unchanged & Worsened & Improved & Unchanged & Worsened \\
\hline \multirow{4}{*}{$\mathbf{T}_{1}$} & NRS & $50(100 \%)$ & - & - & $48(100 \%)$ & - & - \\
\hline & NPDS & $50(100 \%)$ & - & - & $48(100 \%)$ & - & - \\
\hline & SF-MGPQ & $50(100 \%)$ & - & - & $48(100 \%)$ & - & - \\
\hline & NDI & $50(100 \%)$ & - & - & $48(100 \%)$ & - & - \\
\hline \multirow{4}{*}{$\mathbf{T}_{2}$} & NRS & $7(14.0 \%)$ & $38(76.0 \%)$ & $5(10.0 \%)$ & $2(4.2 \%)$ & $18(37.5 \%)$ & $28(58.3 \%)$ \\
\hline & NPDS & $40(80.0 \%)$ & $6(12.0 \%)$ & $4(8.0 \%)$ & $11(22.9 \%)$ & $8(16.7 \%)$ & $29(60.4 \%)$ \\
\hline & SF-MGPQ & $29(58.0 \%)$ & $15(30.0 \%)$ & $6(12.0 \%)$ & $4(8.4 \%)$ & $10(20.9 \%)$ & $34(70.8 \%)$ \\
\hline & NDI & $27(54.0 \%)$ & $16(32.0 \%)$ & $7(14.0 \%)$ & - & $4(8.3 \%)$ & $44(91.7 \%)$ \\
\hline
\end{tabular}

Abbreviations: NDI: Neck Disability Index; NPDS: Neck Pain and Disability Scale; NRS: Numerical Rating Scale; SF-MGPQ: Short Form - McGill Pain Questionnaire.

physical therapy (90\% for NRS, $92 \%$ for NPDS, $88 \%$ for SF-MGPQ, and $86 \%$ for NDI). For patients treated with physical therapy alone, significantly more were worse at follow-up $\left(\mathrm{T}_{2}\right)$ when compared with patients treated with eperisone + physical therapy $(58.3 \%$ versus $10.0 \%$ for NRS, $p<0.001$ [RR=5.8; $95 \%$ CI: $2.5-13.9] ; 60.4 \%$ versus $8.0 \%$ for NPDS, $p<0.001$ [RR=7.6; 95\% CI: 2.9-19.9]; 70.8\% versus $12.0 \%$ for SF-MGPQ, $p<0.001$ [RR $=5.9 ; 95 \%$ CI: $2.7-12.8$ ]; and $91.7 \%$ versus $14.0 \%$ for NDI, $p<0.001$ [RR=6.6; 95\% CI: 3.3-13.1]).

No adverse drug events or reactions were reported.

\section{DISCUSSION}

This was a monocentric clinical study on outpatients with tension-type cervicalgia who were treated with a muscle relaxant drug (eperisone hydrochloride) + physical therapy versus physical therapy alone. Our results show that patients treated with eperisone + physical therapy not only maintained the significant improvement in pain and disabil- ity observed after 4-weeks' treatment, they also benefited from a further, albeit small, improvement at the 2-month follow-up assessment. Although symptoms improved at $\mathrm{T}_{1}$ for all patients treated with physical therapy alone, most of these patients experienced symptom worsening by the end of the 2-month follow-up period. This suggests that the use of physical therapy as a stand-alone treatment does not provide long-term pain relief from tension-type cervicalgia once treatment has ended.

Muscle relaxant drugs including eperisone appear to provide clinically significant short-term pain relief for acute (but not chronic) low back pain $(13,21)$. Indeed, eperisone $100 \mathrm{mg}$ three times daily (t.i.d.) for 12 days $(n=80)$ was shown to be effective and safe for the treatment of acute low back pain due to spasticity of spinal muscles with comparable analgesic and muscle relaxant efficacy to thiocolchicoside $8 \mathrm{mg}$ twice daily $(n=80)$ (22). Treatment with eperisone $100 \mathrm{mg}$ t.i.d. for 10 days also provided consistent beneficial analgesic and muscle relaxant activity in an open-label study of 100 patients with moderate-to-severe, acute or relapsing low 
back pain (23). Eperisone (50 mg t.i.d. for 14 days; $n=112$ ) was also effective and well tolerated compared with placebo $(n=113)$ in patients with low back pain caused by acute musculoskeletal spasm in a randomized, double-blind, placebo-controlled, multi-centric study (24). Significantly fewer eperisone-treated patients required rescue medication for pain relief compared with the placebo group $(p<0.001)$ demonstrating the intrinsic analgesic activity of eperisone. Treatment with eperisone (50 mg t.i.d.; $n=75)$ has also been shown to provide an immediate post-treatment benefit for chronic neck pain with pain in the nuchal region significantly improved $(p<0.005)$ after 6 weeks' treatment compared with placebo $(n=82)$ in patients with cervical spondylosis in a randomized, double-blind, clinical trial (25). However, longer term follow-up was not reported and treatment effects were small (number needed to treat 37, RR 0.68 [95\% CI: 0.52-0.90]) (26).

Eperisone improves blood flow in resting skeletal muscles (27), which may relieve muscle hypoxia due to muscle contracture. Notably, a progressive decontracture of spinal muscles alongside a reduction in both spontaneous and provoked pain was demonstrated in 100 patients with acute low back pain and moderate contracture of the spinal muscles following 10 days' treatment with eperisone $50 \mathrm{mg}$ t.i.d. (28). In addition, significant improvement in paraspinal muscle hemodynamics was demonstrated in patients with chronic low back pain following 4 weeks' treatment with eperisone (50 mg t.i.d.; $n=25$ ) compared with physical therapy only $(n=25)$ or McKenzie therapy $(n=25)$, with improved intramuscular oxygenation during lumbar extension and flexion demonstrated (29). Consequently, the unique ability of eperisone to regulate blood supply to skeletal muscles may relieve the muscle stiffness and pain experienced by patients with tension-type cervicalgia.

The combination of antioxidants ( $\alpha$-lipoic acid/superoxide dismutase) + physiotherapy was shown to be effective in reducing the intensity of pain reported by patients with chronic neck pain compared with physiotherapy alone (30). The successful use of antioxidants (that target nerve inflammation caused by oxidative stress) as an adjuvant therapy to physiotherapy suggests that a multimodal approach may be useful for the management of patients with neck pain. As such, it was of interest to assess the whether the muscle relaxant eperisone in combination with physical therapy was efficacious as a novel multimodal treatment approach. To our knowledge this is the first study to combine eperisone with physical therapy for the treatment of tension-type cervicalgia. We show here that symptoms improved for $14 \%, 80 \%, 58 \%$, and $54 \%$ of patients treated with eperisone + physical therapy based on the NRS, NPDS, SF-MGPQ and NDI scores, respectively, at the end of the 2-month follow-up compared with the end of the 4 -week treatment period. This suggests that eperisone + physical therapy is not only effective in alleviating pain and disability associated with tension-type cervicalgia during treatment but that these positive outcomes are maintained for a period of time after treatment has stopped.

Patients treated with eperisone may be adversely effected by gastrointestinal side effects (nausea, epigastric pain and vomiting), vertigo, light-headedness, dyspnea, mild somnolence, tremor, and dizziness (13). Importantly, no adverse drug events or reactions were experienced in our study. Indeed, a particular advantage of eperisone is its safety and tolerance, which has been demonstrated in a number of studies $(22,28,31)$. In the study by Cabitza and Randelli, fewer adverse drug events were reported in patients treated with eperisone compared with thiocolchicoside $(5 \%$ versus $21 \%$, respectively), highlighting its better tolerability (22). Despite comparable efficacy outcomes between eperisone $(+$ tramadol) and tizanidine $(+$ tramadol $)$ in 60 patients with moderate-to-severe chronic low back pain associated with contractures of paravertebral muscles, eperisone was better tolerated with significantly fewer incidences of somnolence ( $16.6 \%$ versus $43.3 \%$, respectively; $p<0.05$ ) (31). Similarly, no involvement of the central nervous system (i.e., somnolence, reduced cognitive capabilities etc.) was reported by Beltrame and colleagues with adverse reactions to eperisone limited to gastrointestinal disturbances (28). Eperisone may therefore be preferable to other short-acting muscle relaxants due to the low incidence of clinically relevant sedative effects on the central nervous system.

Although this study is limited by its small patient number and the short duration of follow-up, the combination of eperisone + physical therapy appears to be effective for the immediate and sustained relief of pain and disability associated with tension-type cervicalgia.

We believe that eperisone hydrochloride in synergy with physical therapy can be a valuable tool in the therapeutic management of patients suffering from tension-type cervicalgia. High quality, randomized, clinical trials with larger patient populations and longer follow-up are needed to confirm the clinical benefits of eperisone + physical therapy for the treatment of tension-type cervicalgia.

\section{CONFLICTS OF INTERESTS}

The Authors declare that they have no conflicts of interests.

\section{ACKNOWLEDGEMENTS}

Medical writing assistance was provided by Melanie Gatt $(\mathrm{PhD})$, an independent medical writer, on behalf of Spring- 
er Healthcare Communications. Alfasigma provided financial support to cover the cost of this assistance but has not exerted editorial influence over the manuscript content.

\section{REFERENCES}

1. Cote P, Cassidy JD, Carroll LJ, Kristman V. The annual incidence and course of neck pain in the general population: a population-based cohort study. Pain. 2004;112:267-273

2. Murray CJ, Atkinson C, Bhalla K, et al. The state of US health, 1990-2010: burden of diseases, injuries, and risk factors. JAMA. 2013;310:591-608

3. Hogg-Johnson S, van der Velde G, Carroll LJ, et al. The burden and determinants of neck pain in the general population: results of the Bone and Joint Decade 2000-2010 Task Force on Neck Pain and Its Associated Disorders. J Manipulative Physiol Ther. 2009;32:S46-60

4. Lago EP, Estany ER, Delgado JAG, Cordero JM, Acosta TB, Morales IP. Cervicalgia and its Relation to Stress in the Population of a Doctor's Office. J Head Neck Spine Surg. 2018;2:555584

5. Cohen SP. Epidemiology, diagnosis, and treatment of neck pain. Mayo Clin Proc. 2015;90:284-299

6. Childs JD, Cleland JA, Elliott JM, et al. Neck pain: Clinical practice guidelines linked to the International Classification of Functioning, Disability, and Health from the Orthopedic Section of the American Physical Therapy Association. J Orthop Sports Phys Ther. 2008;38:A1-a34

7. Laser Spine Institute. Cervicalgia - overview of causes, symptoms and treatments. https://www.laserspineinstitute.com/ back_problems/neck_pain/overview/cervicalgia/. Accessed 2 May 2018

8. Castelli D, Scaturro D, Sanfilippo A, Mauro GL. Neck Pain Rehabilitation. In: Menchetti PPM, editor. Cervical Spine. Cham: Springer; 2016. p. 237-242

9. MedicalNewsToday. What is cervicalgia and how is it treated? https://www.medicalnewstoday.com/articles/320001.php. Accessed 14 December 2017

10. SouthEastern Spine Institute and Ambulatory Surgical Center. Cervicalgia symptoms and treatment. http://www.southeasternspine.com/spinal-procedures-treatments/spinal-anatomy-and-conditions/cervicalgia/. Accessed 14 December 2017

11. Eperisone RCP. Eperisone Riassunto delle Caratteristiche del Prodotto (Eperisone Summary of Product Characteristics. Revised August 2017). https://farmaci.agenziafarmaco.gov.it/aifa/servlet/PdfDownloadServlet?pdfFileName=footer_004375_028631_RCP.pdf\&retry=0\&sys =m0b113. Accessed 31 Jul 2018

12. Rosso F, Rossi R. Eperisone hydrochloride: new therapeutic evidence for post surgical pain. Minerva Ortopedica e Traumatological. 2016;67:86-93

13. Bavage S, Durg S, Ali Kareem S, Dhadde SB. Clinical efficacy and safety of eperisone for low back pain: A systematic literature review. Pharmacol Rep. 2016;68:903-912.

14. Crue BL, Pinsky JJ. An approach to chronic pain of non-malignant origin. Postgrad Med J. 1984;60:858-864

15. Padulo J, Oliva F, Frizziero A, Maffulli N. Muscles, Ligaments and Tendons Journal - Basic principles and recommendations in clinical and field Science Research: 2016 Update. Muscles Ligaments Tendons J. 2016;6:1-5

16. Monticone M, Baiardi P, Nido N, Righini C, Tomba A, Giovanazzi E. Development of the Italian version of the Neck Pain and Disability Scale, NPDS-I: cross-cultural adaptation, reliability, and validity. Spine (Phila Pa 1976). 2008;33:E429-434

17. Melzack R. The short-form McGill Pain Questionnaire. Pain. 1987;30:191-197

18. Monticone M, Ferrante S, Vernon H, Rocca B, Dal Farra F, Foti C. Development of the Italian Version of the Neck Disability Index: cross-cultural adaptation, factor analysis, reliability, validity, and sensitivity to change. Spine (Phila $\mathrm{Pa}$ 1976). 2012;37:E1038-1044

19. Million R, Nilsen KH, Jayson MI, Baker RD. Evaluation of low back pain and assessment of lumbar corsets with and without back supports. Ann Rheum Dis. 1981;40:449-454

20. Wheeler AH, Goolkasian P, Baird AC, Darden BV, 2nd. Development of the Neck Pain and Disability Scale. Item analysis, face, and criterion-related validity. Spine (Phila $\mathrm{Pa}$ 1976). 1999;24:1290-1294

21. Abdel Shaheed C, Maher CG, Williams KA, McLachlan AJ. Efficacy and tolerability of muscle relaxants for low back pain: Systematic review and meta-analysis. Eur J Pain. 2017;21:228-237.

22. Cabitza P, Randelli P. Efficacy and safety of eperisone in patients with low back pain: a double blind randomized study. Eur Rev Med Pharmacol Sci. 2008;12:229-235.

23. Sartini S, Guerra L. Open experience with a new myorelaxant agent for low back pain. Adv Ther. 2008;25:1010-1018

24. Chandanwale AS, Chopra A, Goregaonkar A, et al. Evaluation of eperisone hydrochloride in the treatment of acute musculoskeletal spasm associated with low back pain: a randomized, double-blind, placebo-controlled trial. J Postgrad Med. 2011;57:278-285

25 . Bose K. The efficacy and safety of eperisone in patients with cervical spondylosis: results of a randomized, double-blind, placebo-controlled trial. Methods Find Exp Clin Pharmacol. 1999;21:209-213

26. Peloso PM, Khan M, Gross AR, et al. Pharmacological Interventions Including Medical Injections for Neck Pain: An Overview as Part of the ICON Project. Open Orthop J. 2013;7:473-493

27. Iwase S, Mano T, Saito M, Ishida G. Effect of a centrally-acting muscle relaxant, eperisone hydrochloride, on muscle sympathetic nerve activity in humans. Funct Neurol. 1992;7:459-470

28. Beltrame A, Grangie S, Guerra L. Clinical experience with eperisone in the treatment of acute low back pain. Minerva Med. 2008;99:347-352

29. Sakai Y, Matsuyama Y, Nakamura H, et al. The effect of muscle relaxant on the paraspinal muscle blood flow: a randomized controlled trial in patients with chronic low back pain. Spine (Phila Pa 1976). 2008;33:581-587

30. Letizia Mauro G, Cataldo P, Barbera G, Sanfilippo A. alpha-Lipoic acid and superoxide dismutase in the management of chronic neck pain: a prospective randomized study. Drugs R D. 2014;14:1-7

31. Rossi M, Ianigro G, Liberatoscioli G, et al. Eperisone versus tizanidine for treatment of chronic low back pain. Minerva Med. 2012;103:143-149 